\title{
Antidepressants and pregnancy: complexities of producing evidence-based information
}

\author{
Adrienne Einarson RN \\ Previously published at www.cmaj.ca
}

$\infty \quad$ See related research article by Nakhai-Pour and colleagues, page 1031, and letter by Bérard and colleagues, page 1079

$\mathrm{T}$ he prevalence for depression in women peaks during the childbearing years, from the age of 25 to 44 years, and can occur in up to $15 \%$ of all pregnant women. ${ }^{\prime}$ Untreated depression during pregnancy has been reported to increase the risk of preterm delivery and other adverse obstetric events and may require pharmacologic treatment. ${ }^{2}$

Before 2005, evidence-based literature on pregnancy outcomes associated with the use of antidepressants was scarce, although reassuring. ${ }^{3}$ Since then, there has been large increase in the number of studies, often with conflicting results, which has increased apprehension about both prescribing and taking antidepressants during pregnancy. The precedent-setting jury trial in September 2009 - when the parents of a boy born with a cardiovascular defect following exposure to antidepressants in utero, were awarded $\$ 2.5$ million to be paid by GlaxoSmithKline Inc., the manufacturers of paroxetine - did little to settle the conflict, because the decision was based on opinion rather than on evidence. ${ }^{4}$

Studying the safety of drugs taken during pregnancy is complex; most women are not going to volunteer to participate in a randomized controlled trial to study a new drug. Therefore, most studies are of observational design (e.g., case reports, case series, cohort studies, case-control and nested case-control studies and administrative database studies). There is no gold standard for studying the safety of drugs taken during pregnancy.

Nakhai-Pour and colleagues, in a study published in this issue, ${ }^{5}$ illustrate the complexity of this area of research. Their study used prescription data (confirmation that a prescription has been dispensed, not necessarily that the medication has been taken) linked to a physician's diagnosis from the Quebec Pregnancy Registry. They used a nested case-control design, whereby they obtained data on 5124 women who had had a spontaneous abortion. Of the 5124 women, 284 (5.5\%) had had a prescription filled for an antidepressant. The authors found that use of antidepressants during pregnancy was associated with a $68 \%$ increase in risk of spontaneous abortion (odds ratio [OR] 1.68, 95\% confidence interval [CI] 1.38-2.06). They also calculated a higher risk associated with use of paroxetine, venlafaxine and combinations of antidepressant classes.

When interpreting the results of these types of epidemiologic studies, especially case-control studies that have a con-

\section{Key points}

- Depression occurs in up to $15 \%$ of all pregnant women.

- Treatment with antidepressants may be unavoidable, thereby forcing physicians to make prescribing decisions with little evidence-based information to guide them.

- Results from studies that use different methods to examine the safety of antidepressants taken during pregnancy vary in their differences and similarities.

- If there is a true increased risk of spontaneous abortion caused by gestational use of antidepressants, it is very small.

fusing array of statistics, readers should be aware that multiple analyses are conducted; there were more than 100 in the study by Nakhai-Pour and colleagues. With each analysis, there is a 5\% chance of a false-positive result, or, as the authors stated, chance findings.

All study designs have strengths and limitations, some of which the authors discussed. However, several of the strengths that were described are not possible. First, at no point were the women in the study interviewed to determine whether they took the medication; my colleagues and I at Motherisk (a teratology information service) have found that patients have prescriptions filled but never take the drug, especially if they discover they are pregnant. This is especially common with psychiatric drugs because they are perceived to be more harmful than other drugs. ${ }^{6}$ Second, many women who have a spontaneous abortion, even of a recognized pregnancy, do not visit a physician, so there would not be a physician's diagnosis. This probably explains the low rate of spontaneous abortion in the study (7.3\%), which was considerably lower than that in other studies $(25 \%))^{7.8}$

Third, Nakhai-Pour and colleagues' attempt to adjust for confounding by indication (i.e., depression) was not possible (nor was it in the Motherisk study') because there were not enough relevant data. The only appropriate way to control for depression would be to conduct a prospective, longitudinal comparative study with a large enough sample size and three

Adrienne Einarson is Assistant Director of the The Motherisk Program, The Hospital for Sick Children, Division of Clinical Pharmacology, University of Toronto, Toronto, Ont.

CMAJ 2010. DOI:10.1503/cmaj.100507

All editorial matter in CMAJ represents the opinions of the authors and not necessarily those of the Canadian Medical Association. 


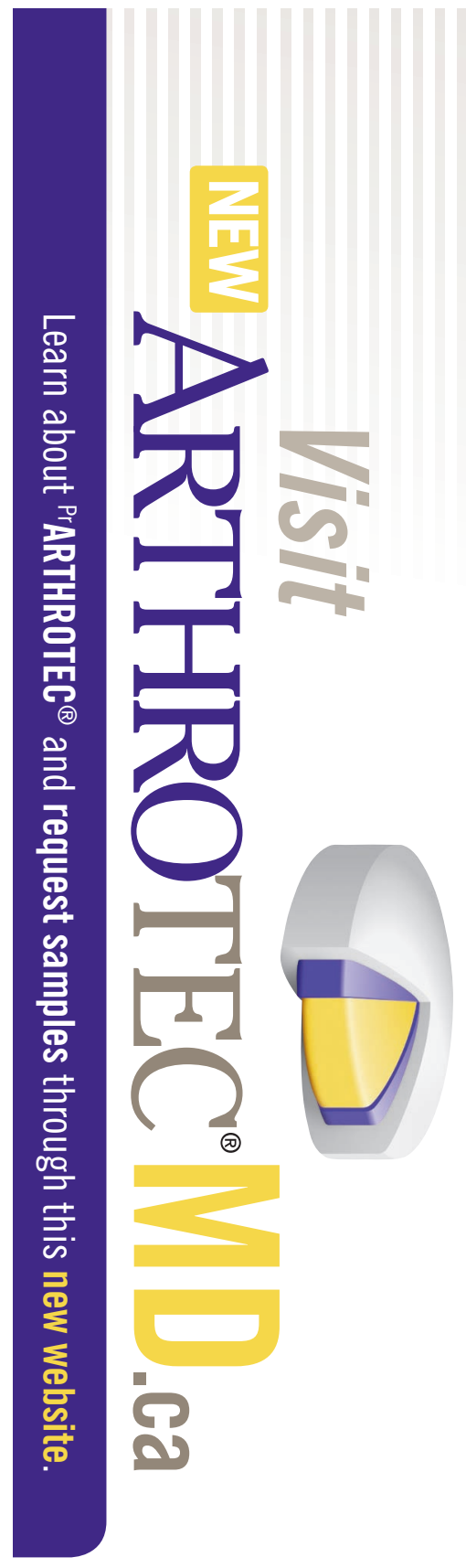

An NSAID with a mucosal protective agent, ${ }^{\text {PrARTHROTEC }}{ }^{\circledR}$ (50 \& $75 \mathrm{mg}$ diclofenac sodium and misoprostol tablets) has contraindications as wel as warnings and precautions of use.

Please consult the Prescribing Information which is available on the ARTHROTECMD.ca website, or the Product Monograph which is available upon request.

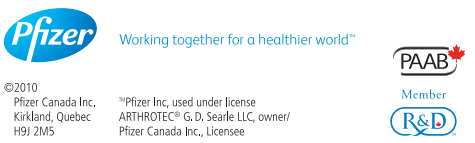

\section{COMMENTARY}

matched groups of pregnant women - those depressed and treated with an antidepressant, those depressed and untreated, and those not depressed. To date, no such studies with a large enough sample size have been published.

In conclusion, a combination of methods can be used to produce evidence-based information on the safety of drugs during pregnancy, provided the study design is rigorous and the limitations are stated clearly. Motherisk used a very different model (a prospective comparative cohort with 937 treated with antidepressants and 937 untreated), ${ }^{9}$ and the results were almost identical to those reported by NakhaiPour and colleagues. However, their finding of an increased risk of spontaneous abortion associated with paroxetine, venlafaxine and combinations of antidepressants is based on very small numbers and, as the authors stated, the results should be interpreted with caution.

Clearly, this study cannot make any definitive conclusions as to whether antidepressants increase the risk of spontaneous abortion. However, there does appear to be a very small increase: less than two-fold for spontaneous abortion among women exposed to antidepressants, compared with those nonexposed. Physicians caring for pregnant women who require pharmacologic treatment for depression should discuss the risks and benefits of taking antidepressants; the evidencebased information from this study will help in the decisionmaking by the patient.

Competing interests: Adrienne Einarson and Motherisk are conducting research funded by an unrestricted grant from Eli Lilly Canada Inc.

\section{REFERENCES}

1. Muzik M, Marcus SM, Heringhausen JE et al. When depression complicates childbearing: guidelines for screening and treatment during antenatal and postpartum obstetric care. Obstet Gynecol Clin North Am 2009;36:771-88.

2. Yonkers KA, Wisner KL, Stewart DE, et al. The management of depression during pregnancy: a report from the American Psychiatric Association and the American College of Obstetricians and Gynecologists [review]. Obstet Gynecol 2009;114: 703-13.

3. Einarson TR, Einarson A. Newer antidepressants in pregnancy and rates of major malformations: a meta-analysis of prospective comparative studies. Pharmacoepidemiol Drug Saf 2005;14:823-7.

4. Tanne JH. GlaxoSmithKline told to pay family $\$ 2.5 \mathrm{~m}$ after jury finds paroxetine caused son's heart defects. BMJ 2009;339:b4266.

5. Nakhai-Pour HR, Broy P, Bérard A . Antidepressant use during pregnancy and the risk of spontaneous abortion. CMAJ 2010;182:1031-7.

6. Bonari L, Koren G, Einarson TR, et al. Use of antidepressants by pregnant women: evaluation of perception of risk, efficacy of evidence based counseling and determinants of decision making. Arch Womens Ment Health 2005;8:214-20.

7. Hemminki E. Treatment of miscarriage: current practice and rationale. Obstet Gynecol 1998;91:247-53.

8. Regan L, Rai R. Epidemiology and the medical causes of miscarriage. Baillieres Best Pract Res Clin Obstet Gynaecol 2000;14:839-54.

9. Einarson A, Choi J, Einarson TR, et al. Rates of spontaneous and therapeutic abortions following use of antidepressants in pregnancy: results from a large prospective database. J Obstet Gynaecol Can 2009;31:452-6.

Correspondence to: Dr. Adrienne Einarson, The Motherisk Program, The Hospital for Sick Children, Division of Clinical Pharmacology, University of Toronto, 550 University Ave., Toronto ON M5G 1X8; einarson@sickkids.ca 